\title{
Dendritic Cell-based Immunotherapy Pulsed With Wilms Tumor 1 Peptide and Mucin 1 as an Adjuvant Therapy for Pancreatic Ductal Adenocarcinoma After Curative Resection: A Phase I/IIa Clinical Trial
}

\author{
KAZUHIRO NAGAI $^{{ }^{*}}$, TOMOHIKO ADACHI ${ }^{2 *}$, HIROSHI HARADA ${ }^{1}$, \\ SUSUMU EGUCHI ${ }^{2}$, HARUO SUGIYAMA ${ }^{3}$ and YASUSHI MIYAZAKI ${ }^{1,4}$ \\ ${ }^{1}$ Transfusion and Cell Therapy Unit, Nagasaki University Hospital, Nagasaki, Japan; \\ ${ }^{2}$ Department of Surgery, Nagasaki University Hospital, Nagasaki, Japan; \\ ${ }^{3}$ Department of Cancer Immunology, Osaka University Graduate School of Medicine, Osaka, Japan; \\ ${ }^{4}$ Department of Hematology, Atomic Bomb Disease Institute, Nagasaki University, Nagasaki, Japan
}

\begin{abstract}
Background/Aim: We evaluated the safety, feasibility, and preliminary efficacy of Wilms tumor gene 1 (WT1) peptide and Mucin 1 (MUC1)-pulsed dendritic cell (DC) (WT1/MUC1-DC) vaccination as an adjuvant immunotherapy for surgically resectable pancreatic ductal adenocarcinoma (PDA) patients. Patients and Methods: Eligible patients were administered WT1/MUC1-DC vaccination at least seven times every 2 weeks with concomitant adjuvant chemotherapy after surgical resection of PDA. Results: Ten patients were enrolled and no Grade 2 or higher toxicities were associated with DC vaccination. The estimated overall survival (OS) and relapsefree survival (RFS) at 3-years from the time of surgical resection were $77.8 \%$ and $35.0 \%$, respectively. Immunohistochemical analysis suggested a possible relationship between induction of WT1-specific cytotoxic T lymphocyte after DC vaccination and higher infiltration of $C D 3 / C D 4 / C D 8$ lymphocytes in tumor tissues. Conclusion: WT1/MUC1-DC vaccination in the adjuvant setting was safe and well-tolerated in PDA patients after tumor resection. A large-scale prospective study is warranted to evaluate the clinical benefit of this modality.
\end{abstract}

This article is freely accessible online.

*These Authors contributed equally to this work.

Correspondence to: Kazuhiro Nagai, MD, Ph.D., Transfusion and Cell Therapy Unit, Nagasaki University Hospital, 1-7-1 Sakamoto, Nagasaki, 852-8501 Japan. Tel: +81 958197455, Fax: +81 938197457,e-mail: agwkn@nagasaki-u.ac.jp

Key Words: Pancreatic ductal adenocarcinoma, dendritic cell vaccination, WT1, MUC1, phase I/IIa study.
Pancreatic ductal adenocarcinoma (PDA) has been identified as an extremely aggressive malignant tumor. Most patients have relatively advanced disease at the time of diagnosis (1, 2 ). In spite of surgical resection being the only curative option, only a small fraction of patients with PDA present with resectable disease, and the 5-year overall survival (OS) rate remains at around $10 \%-15 \%$ after curative resection (1, $3)$. Although many cytotoxic drugs have been proven effective in treating this disease and are often used as adjuvant therapy after surgery, the median progression-free survival is still limited. Five-year survival rates remain inadequate at about $15 \%-25 \%$ using modern multimodal treatment strategies. Therefore, there is an urgent need to devise novel strategies for PDA treatment.

Recently, immunotherapy has been proposed as a new treatment approach for such cancers with poor prognosis including PDA (4), and various methods have been considered. Selection of a tumor-associated antigen (TAA) is an important consideration in cancer immunotherapy. The ideal TAA target should be expressed only on tumor cells, as they have very limited expression on normal tissues, and will produce the greatest effect on tumor cell survival. In a pilot project conducted to prioritize 75 known cancer antigens for this purpose, Wilms tumor gene 1 (WT1) antigen was identified as the most suitable (5). WT1 has been originally defined as a tumor suppressor gene encoding a zinc finger DNA-binding protein (6), which is involved in tumorigenesis through transcriptional regulation of several genes (7-9). The WT1 antigen is highly expressed in various malignancies, including PDA (10), and can have oncogenic functions (11). MUC1 (mucin-1, CD227) is a polymorphic, glycosylated type I transmembrane protein present in the glandular epithelium of different tissues, including the pancreas, breast, 
and lung, and it has been reported to be over-expressed in $90 \%$ of PDA tumors (12-14). MUC1 inhibits cell-cell and cell-stroma interactions and functions as a signal transducer promoting cancer progression characterized by tumor invasion and metastasis (15). Most tumor antigens are characterized by major histocompatibility complex (MHC)restriction, whereas MUC1 recognition by cytotoxic Tlymphocytes (CTL) is not MHC-restricted. Furthermore, MUC1 has also been reported as a highly promising TAA for cancer immunotherapy (5). Therefore, WT1 and MUC1 have been used as immunotherapy targets for PDA.

Dendritic cells (DC) are widely considered to be the most efficient antigen-presenting cells responsible for $\mathrm{T}$ cell activation and are the link between innate and adaptive immunity (16). With the identification of TAAs, TAA-pulsed autologous DCs generated ex vivo by culturing monocytes with cytokine combinations have been used for therapeutic cancer vaccination (17). Comparative studies have suggested that TAA peptide-pulsed DC vaccines may elicit more CTL activity than peptides alone (18). Numerous studies suggest that DC-based vaccination is an ideal modality for immunotherapy for cancers including PDA (19, 20). However, most clinical trials regarding PDA have targeted advanced disease; thus, the significance of this therapeutic modality in surgically resectable patients remains to be unresolved.

Here, we conducted a phase I/IIa clinical study of WT1 peptide and MUC1-pulsed DC (WT1/MUC1-DC) vaccination as an adjuvant immunotherapy for resectable PDA patients. In addition to evaluating the feasibility, safety, and antitumor efficacy of this therapy, we evaluated various immunological parameters that may be correlated with the induction of immune responses and antitumor effects. In particular, we have focused on the immunological characteristics of the tumor microenvironment using immunohistochemical methods on resected tumor tissues.

\section{Patients and Methods}

Study design. This phase I/IIa open-label study was conducted between June 1, 2013 and February 6, 2019. The primary objectives of the study were to evaluate the safety, tolerability, and feasibility of DC-based vaccination pulsed with WT1 peptide and MUC1 as an adjuvant therapy for enrolled patients who underwent their respective operations for pancreatic cancer. The secondary objective was to evaluate potential predictive immunological and histochemical biomarkers associated with clinical activity and/or safety. The cutoff for data collection was December 31, 2018.

Patients. Candidates for this study were consecutively enrolled during the registration period. Eligible patients met the following criteria: 18 to 80 years of age, were diagnosed with PDA, underwent respective operations after initial diagnosis, had Eastern Cooperative Oncology Group performance status (PS) of 0-1, had normal organ function, had no chemotherapy-disqualifying sign of infectious disease, had no blood abnormality or bleeding tendency, had no apheresis-disqualifying history of cardiovascular disease or respiratory disorders, and had human leukocyte antigen (HLA) class I genotypes compatible with restriction of the WT1 peptide. Furthermore, we confirmed the expression of WT1 protein and HLA class I (ABC) in resected PDA tissue using the immunohistochemical (IHC) methods described below in advance of registration. Expression of both proteins in PDA cells was required for registration to this study. Patients who received chemotherapy before surgery or were diagnosed within 6 months with other cancers were excluded from the study.

Production of WT1 peptide and MUC1-loaded DC vaccine. The WT1/MUC1-DC vaccine was prepared as previously reported (21), by a well-trained technical staff in the cell processing facility (CPF) of Nagasaki University Hospital under standard operating procedures (SOP) compliant with Good Gene, Cellular, and Tissuebased Products Manufacturing Practice. Briefly, leukapheresis was carried out when patients' peripheral white blood cell (WBC) count, hemoglobin concentration, and platelet count were above 2000 cells $/ \mu \mathrm{l}, 9.0 \mathrm{~g} / \mathrm{dl}$, and 90,000 cells $/ \mu 1$, respectively. Peripheral blood mononuclear cells (PBMNCs) were isolated from leukapheresis products by Ficol-Hypaque (GE Healthcare Japan, Tokyo, Japan) gradient density centrifugation. PBMNCs were then cultured in tissue-culture plates, and adherent cells were harvested. Adherent cells were cultured in AIM-V medium (Gibco/Thermo Fisher Scientific, Yokohama, Japan) containing human recombinant granulocyte-macrophage-colony-stimulating factor (GM-CSF, 50 $\mathrm{ng} / \mathrm{ml}$, NCPC Genetech, Shijiazhuang, China) and human recombinant interleukin-4 (IL-4, $50 \mathrm{ng} / \mathrm{ml}$, R\&D Systems, Minneapolis, MN, USA) in order to generate immature DCs. Five days later, DCs were loaded with HLA-A*24:02-restricted WT1 (235-243: CYTWNQMNL) (mutant WT1 peptide, Neo-MPS; San Diego, CA, USA) and HLA-A*02:01/02:06-restricted WT1 peptide (126-134: RMFPNAPYL) (WT1 peptide, Neo-MPS) according to the compatibility of each patient's HLA typing. DCs were then stimulated with OK-432, streptococcal preparation $(10 \mu \mathrm{g} / \mathrm{ml}$, Chugai Pharmaceutical, Tokyo, Japan), prostaglandin E2 (PGE2, 50 ng/ml, Daiichi Fine Chemical, Tokyo, Japan), IL-4 (5 ng/ml), and granulocyte-macrophage colony-stimulating factor $(5 \mathrm{ng} / \mathrm{ml})$ for 24 $\mathrm{h}$ for maturation. MUC1 was added to the DC culture media concomitantly with OK-432 and PGE2. The MUC1 long peptide TRPAPGSTAPPAHGVTSAPDTRPAPGSTAP (Greiner Japan, Tokyo) was used for all HLA-A types. DCs were harvested, washed, and dissolved in AIM-V medium containing 10\% dimethyl sulfoxide (DMSO, Nipro, Osaka, Japan) and 10\% human albumin (Nihon Pharmaceutical, Osaka, Japan) and dispensed to cryo-tubes at approximately $1 \times 10^{7}$ cells per tube. After pre-freezing at $-80^{\circ} \mathrm{C}$ for $4 \mathrm{~h}$, DCs were cryo-preserved at $-150^{\circ} \mathrm{C}$ in a deep freezer until the day of administration.

Criteria for DC vaccine release. Flow cytometry was used to determine the antigenic profiles of mature DCs. Mature DCs were defined as $\mathrm{CD} 11 \mathrm{c}^{+}, \mathrm{CD} 14^{-}, \mathrm{HLA}_{-} \mathrm{DR}^{+}, \mathrm{HLA}-\mathrm{ABC}^{+}, \mathrm{CD}^{+} 0^{+}$, $\mathrm{CD}^{2} 3^{+}, \mathrm{CD}_{86}{ }^{+}, \mathrm{CD} 40^{+}$, and $\mathrm{CCR} 7^{+}$cells. The following criteria were required for $\mathrm{DC}$ vaccine administration: purity (proportion of CD11 $\mathrm{c}^{+}, \mathrm{CD} 14-, \mathrm{CD}^{2} 6^{+}$, and HLA-DR ${ }^{+}$cells $\left.>90 \%\right),>80 \%$ viability, mature DC phenotype, negative for bacterial and fungal infection after 14 days, endotoxin $\leq 0.05 \mathrm{EU} / \mathrm{ml}$, and negative for mycoplasma. 


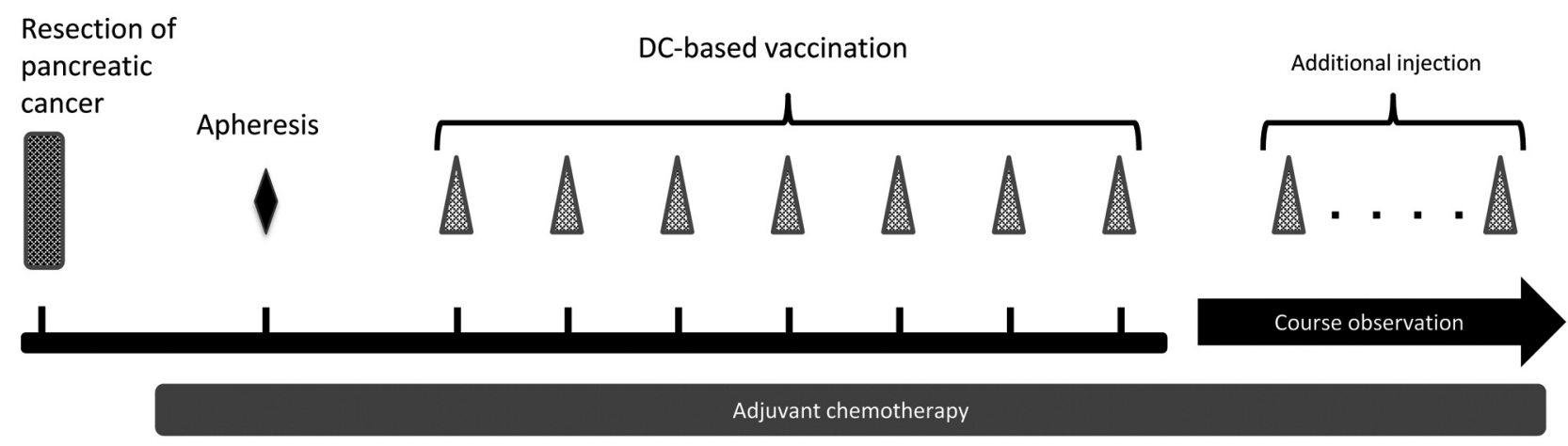

Figure 1. Treatment protocol schema. Harvested PBMNCs were processed and cultured for 14 days at the CPF of Nagasaki University Hospital. Cell products underwent quality inspections and were confirmed to meet shipping criteria. WT1 peptide and MUC1-pulsed DC (10 7 cells/injection) were injected intradermally at least seven times every 2 weeks. Concomitant administration of adjuvant chemotherapeutic agents was allowed in this study.

Treatment. A schematic of the trial design is given in Figure 1. The vaccination regimen has been described previously (21). Briefly, cryo-preserved DCs were thawed, washed with physiological saline (Otsuka Pharmaceutical, Tokyo, Japan) containing 10\% dextran (10 $\mathrm{mL}$, Otsuka Pharmaceutical) once, and washed with physiological saline $(10 \mathrm{ml})$ twice to get rid of the remaining DMSO and human albumin. WT1/MUC1-DCs were suspended in a total volume of 1 $\mathrm{ml}$ of physiological saline, and approximately $1 \times 10^{7}$ WT1/MUC1DCs were injected intradermally at four positions in the axilla and groin regions on each side (approximately $0.25 \mathrm{ml}$ at each position). They were administered seven times in 2-week intervals. OK-432 was administered subcutaneously in each axilla $(0.5 \mathrm{ml}$ each $)$ in the vicinity of vaccination sites to activate DC functions. Administration was initiated at a dose of 1 Klinische Einheit (KE, clinical unit) and increased to $5 \mathrm{KE}$ if no side effects were observed.

In this study, concurrent adjuvant chemotherapy was acceptable. Chemotherapy was selected by the referring surgeons and included the oral tegafur-gimeracil-oteracil potassium combination agent S1 in eight patients and gemcitabine (GEM) in one patient. S-1 was administered orally at a daily dose of $80-120 \mathrm{mg}$ for $14-28$ days with 1-2 weeks rest repeated every 3-6 weeks. GEM $100 \mathrm{mg} / \mathrm{m}^{2}$ was administered on day 1 and repeated every 3 weeks with 1-2 weeks rest. In one patient, no adjuvant chemotherapy was administered because of the patient's refusal.

Evaluation of adverse events (AEs). AEs were monitored and graded according to the National Cancer Institute's Common Terminology Criteria for Adverse Events Version 5.0 (CTCAE ver.5.0), including hematological (leukocytopenia, neutropenia, anemia, and thrombocytopenia) and non-hematological AEs (fatigue, nausea, diarrhea, constipation, anorexia, pain, hypertension, stomatitis, hematuria, pollakiuria, micturition pain, neurological symptoms, fever and abnormality in kidney function, electrolytes, or liver function) during or after treatment completion until the end of this study (22). Skin reactions at the injection site and fever, which are known AEs resulting from DC administration, were assessed after 24, 48, and 72 $\mathrm{h}$ after each vaccination in all patients. Furthermore, safety evaluations were undertaken for allergic reactions after intradermal injection of DC vaccine. Monitored symptoms included the presence of reduced blood pressure, tachycardia, breathing difficulties, or urticaria.
Evaluation of clinical response. The analysis of target populations in this study were as follows: 1) maximum analysis target group (cases excluded from eligible cases that did not receive therapy), 2) safety analysis target population (the maximum analysis target population), and 3) progression-free and overall survival analysis target cases (the maximum analysis population).

We evaluated OS and relapse-free survival (RFS) at 3 years postsurgery, which was concomitant with the induction of WT1-specific CTLs during DC vaccination targeting WT1 in pancreatic cancer. Imaging techniques including computed tomography and positronemission tomography/computed tomography were also used for post-surgical assessment of lesions. The clinical response after administration of the WT1-DC vaccine was determined according to Response Evaluation Criteria in Solid Tumors (version 1.1) (RECIST v1.1) (23). RFS has been defined as the lesser of the number of days until relapse of disease as determined by RECIST criteria or the number of days until death. RECIST criteria were evaluated 4 weeks after the final administration. After that, evaluation was repeated until relapse was determined. The followup period was 2 years from the first administration of DC vaccination for each participant.

Evaluation of WT1-specific CTLs. PBMNCs were obtained before initiating the first vaccination and at the completion of the seventh vaccination. The WT1 tetramer assay was performed only in patients who received the HLA-A*24:02-restricted mutant WT1 peptide. WT1 tetramer was assessed in the CD3/CD8 doublepositive population using WT1-modified peptides/HLA-A*24:02 tetramers (MBL, Medical \& Biological Laboratories Co., Ltd., Nagoya, Japan) (24).

IHC analysis of primary tumor samples. We analyzed resected samples of pancreas tumor from enrolled patients using a previously described IHC method $(24,25)$. For expression analysis of WT1 and HLA-ABC proteins in tumor cells, we used mouse monoclonal antiWT1 (6F-H2; Dako, Carpinteria, CA, USA) and anti-HLA-ABC antigen antibodies (class I, W6/32; Dako). Negative control staining was applied to all samples using a mouse $\mathrm{IgG}$ isotype control monoclonal antibody (X0931; Dako). The intensity of WT1 protein expression observed in PDA cells was classified as follows: (i) 
Table I. Clinical characteristics of registered cases.

\begin{tabular}{|c|c|c|c|c|c|c|c|c|c|c|c|c|c|c|c|}
\hline $\begin{array}{l}\text { Patient } \\
\text { No. }\end{array}$ & Gender & Age & $\begin{array}{l}\text { Differentiation } \\
\text { of PDA }\end{array}$ & $\begin{array}{l}\text { Stage } \\
\text { at } d x\end{array}$ & PS & $\begin{array}{l}\text { Albumin } \\
(\mathrm{g} / \mathrm{dl})\end{array}$ & $\begin{array}{l}\text { WBC } \\
(/ \mathrm{mcl})\end{array}$ & $\begin{array}{l}\text { Neutrophil } \\
(/ \mathrm{mcl})\end{array}$ & $\begin{array}{c}\text { CRP } \\
(\mathrm{mg} / \mathrm{dl})\end{array}$ & $\begin{array}{l}\mathrm{LDH} \\
(\mathrm{IU} / \mathrm{l})\end{array}$ & BMI & PNI & NLR & $\begin{array}{c}\text { WT1 } \\
\text { expression in } \\
\text { tumor cells }\end{array}$ & $\begin{array}{c}\text { Adjuvant } \\
\text { chemo- } \\
\text { therapy }\end{array}$ \\
\hline 1 & $\mathrm{~F}$ & 76 & Well & IIA & 1 & 4 & 6,600 & 2,970 & 0.06 & 191 & 17.4 & 53.85 & 1.07 & Strong & GEM \\
\hline 2 & M & 65 & Poorly & III & 0 & 3.7 & 6,500 & 2,860 & 0.16 & 149 & 19.9 & 50.65 & 1.05 & Moderate & Not done \\
\hline 3 & M & 56 & Well & IA & 0 & 4.6 & 7,400 & 4,510 & 0.1 & 145 & 25 & 57.1 & 2.03 & Strong & TS-1 \\
\hline 4 & M & 62 & Poorly & IIB & 0 & 4.6 & 5,100 & 2,090 & 0.01 & 128 & 17.7 & 58.5 & 0.84 & Strong & TS-1 \\
\hline 5 & $\mathrm{~F}$ & 60 & Moderately & IIB & 0 & 4.4 & 17,500 & 15,580 & 0.04 & 158 & 14.8 & 50.2 & 12.7 & Weak & TS-1 \\
\hline 6 & M & 63 & Moderately & IIB & 0 & 4.2 & 5,800 & 3,420 & 0.02 & 132 & 21.5 & 50.1 & 2.11 & Weak & TS-1 \\
\hline 7 & M & 62 & Moderately & IIA & 0 & 4.6 & 6,000 & 2,940 & 0.02 & 226 & 18.8 & 58.3 & 1.20 & Moderate & TS-1 \\
\hline 8 & M & 64 & Well & IIB & 0 & 4 & 8,600 & 6,880 & 0.08 & 175 & 22.4 & 43.85 & 3.32 & Moderate & TS-1 \\
\hline 9 & M & 59 & Poorly & IIB & 0 & 3.4 & 4,600 & 1,980 & 0.04 & 151 & 20.2 & 43.9 & 6.68 & Weak & TS-1 \\
\hline 10 & $\mathrm{~F}$ & 64 & Moderately & IIB & 1 & 3.8 & 4,250 & 3,180 & 0.1 & 206 & 17.7 & 40.1 & 3.90 & Weak & TS-1 \\
\hline
\end{tabular}

Clinical staging was classified in accordance with Classification of Pancreatic Carcinoma by Japan Pancreas Society, 4th $^{\text {th }}$ version, 2017. GEM: Gemcitabine; BMI: body mass index: weight $(\mathrm{kg}) /$ height $^{2}(\mathrm{~m})$; PNI: prognostic nutrition index $=10 \times \mathrm{Alb}(\mathrm{g} / \mathrm{dl})+0.005 \times 1 \mathrm{ymphocyte}(/ \mu \mathrm{l})$; NLR: neutrophil $(/ \mu \mathrm{l}) / \mathrm{lym}$ phocyte $(/ \mu \mathrm{l})$ ratio; WT1 expression in tumor cells was analyzed by immunohistochemical methods. The intensity of WT1 protein expression observed in the PDA cells was classified as follows: (i) negative, no staining in PDA cells; (ii) weak, faint, and barely perceptible cytoplasmic staining was observed in PDA cells under 200× magnification; (iii) moderate, moderate complete cytoplasmic staining was observed in PDA cells under 40× magnification; and (iv) strong, strong complete cytoplasmic staining was observed in PDA cells under low magnification.

Table II. Production and administration profile of DC vaccination.

\begin{tabular}{|c|c|c|c|c|c|c|c|c|}
\hline \multirow{2}{*}{$\begin{array}{l}\text { Patient } \\
\text { No. }\end{array}$} & \multirow{2}{*}{$\begin{array}{l}\text { Harvested } \\
\text { volume } \\
\quad(\mathrm{ml})\end{array}$} & \multirow{2}{*}{$\begin{array}{l}\text { Total MNC } \\
\text { collection } \\
\left(\times 10^{7}\right)\end{array}$} & \multicolumn{2}{|c|}{ WT1 peptide } & \multirow{2}{*}{$\begin{array}{c}\text { Viability at } \\
\text { vaccination } \\
(\%)\end{array}$} & \multirow{2}{*}{$\begin{array}{l}\text { DC injection } \\
\text { (times) }\end{array}$} & \multirow{2}{*}{$\begin{array}{l}\text { Total No. of } \\
\text { injected DCs } \\
\quad\left(\times 10^{7}\right)\end{array}$} & \multirow{2}{*}{$\begin{array}{c}\text { OK432 } \\
\text { (KE) }\end{array}$} \\
\hline & & & Class I *2402 & Class I *0201 & & & & \\
\hline 1 & 212 & 339.0 & Yes & No & 87.4 & 7 & 25.1 & 18.5 \\
\hline 2 & 172 & 628.0 & Yes & No & 91.3 & 7 & 11.3 & 20.5 \\
\hline 3 & 173 & 814.0 & Yes & No & 93.8 & 7 & 22.5 & 20.5 \\
\hline 4 & 170 & 451.0 & Yes & Yes & 86.6 & 7 & 27.8 & 20.5 \\
\hline 5 & 190 & 382.0 & No & No & 90.4 & 12 & 19.7 & 23 \\
\hline 6 & 210 & 496.0 & Yes & No & 85.1 & 7 & 18.3 & 18 \\
\hline 7 & 195 & 521.0 & No & Yes & 83.2 & 9 & 22.6 & 21.5 \\
\hline 8 & 184 & 600.0 & No & No & 90.8 & 7 & 26.0 & 18 \\
\hline 9 & 220 & 731.0 & Yes & No & 94.8 & 7 & 20.4 & 18 \\
\hline 10 & 218 & 766.0 & Yes & No & 80.8 & 9 & 28.0 & 21.5 \\
\hline
\end{tabular}

negative; (ii) weak, faint, and barely perceptible cytoplasmic staining; (iii) moderate, moderate complete cytoplasmic staining; and (iv) strong, strong complete cytoplasmic staining (25). In addition, to analyze the immunophenotypes of tumor-infiltrating mononuclear cells, we used monoclonal antibodies binding CD20 (L26; Dako), CD3 (LN10; Leica, Nussloch, Germany), CD4 (1F6; Leica), CD8 (4B11; Leica), CD25 (4C9; Leica), FOXP3 (SP97; AbCam, Cambridge, UK), TIA1 (2G9A10F5; Beckman Coulter, Brea, CA, USA), and Programmed Cell Death-1 (PD1) (NAT105; AbCam) for these analyses. Observation was carried out using high-magnification light microscopy (400x). Expression was scored as negative if $<5 \%$ of cells were positive, $1+$ if $5 \%$ to $10 \%$ of cells were positive, $2+$ if $10 \%$ to $30 \%$ were positive, $3+$ if $30 \%$ to $60 \%$ were positive, and $4+$ if $>60 \%$ were positive. Two investigators who were not privy to the requisite clinical information independently interpreted the IHC results.
Statistical analysis. We compared the results of tetramer assays before and after administration of the WT1-DC vaccine using the Wilcoxon signed-rank test. We used a Kaplan-Meier curve to evaluate OS and RFS and compared those measures between groups using the log-rank test. All statistical analyses were performed using EZR (Saitama Medical Center, Jichi Medical University, Saitama, Japan). A p-value of less than 0.05 was considered statistically significant.

Ethics statement. The protocol for WT1-DC vaccination therapy at the Nagasaki University Hospital was approved by the Ethics Committee of Nagasaki University School of Medicine (approval number: 12102231). The Act on the Safety of Regenerative Medicine in Japan was enforced on November 25, 2014. Class III technologies were regarded as low-risk since they used somatic cells and accumulated clinical experiences. DC vaccination therapy 
(Class III technology) at the Nagasaki University was approved on November 25, 2015 (approval number: PC3150643). Written informed consent was obtained from all the patients. All procedures performed in this study were in accordance with the Ethical Guidelines for Medical and Health Research involving Human Subjects proposed by the Ministry of Health, Labour and Welfare in Japan (26). The trial was registered with the University Hospital Medical Information Network (UMIN) Clinical Trials Registry (27).

\section{Results}

Characteristics of enrolled patients. Table I shows the clinicopathological characteristics of the patients who were enrolled in the present study. Patients' ages ranged from 56 to 76 years old (median 62.5 years old), and their PS was well maintained. Clinical stage varied from IA to III (28) and curative resection was performed in all cases. Laboratory data regarding $\mathrm{C}$-reactive protein (CRP), neutrophil-tolymphocyte ratio (NLR), and prognostic nutritional index (PNI) were obtained for all patients. In the present setting, stable nutritional status was indicated, and NLR and $\mathrm{CRP} /$ albumin ratios indicated only minimal inflammatory status in all patients after resection (Table I).

Expression of WT1 and HLA-ABC in the surgical specimens of all the 10 patients with pancreatic cancer was confirmed. We classified IHC staining intensity of cytoplasmic WT1 in tumor cells into three categories, weak, moderate, and strong, as described by Kanai et al. (25). Strong, moderate, and weak staining patterns were observed in four, four, and two of ten cases, respectively.

DC-based vaccine preparation and characterization. Table II shows data related to the preparation of the DC-based vaccine. Apheresis of monocytes from peripheral blood was carried out in all patients. There were no adverse responses during apheresis. The numbers of harvested PBMNCs ranged from $339.0 \times 10^{7}$ to $814.0 \times 10^{7}$ cells (median $560.5 \times 10^{7}$ cells), allowing to reach the target cell number required to prepare and ship DC products.

Mature DCs were injected at a dose of $11.3 \times 10^{7}$ to $28.0 \times 10^{7}$ cells per vaccination (median $22.5 \times 10^{7}$ ). Seven patients received WT1 peptide-pulsed vaccination restricted to HLA-A*24:02. Patients received 7-12 vaccinations (median 7). The total dose of OK-432 was 18-23 KE (median 20.5 $\mathrm{KE}$ ). The maximum dose of OK-432 per session was $5 \mathrm{KE}$.

Safety and toxicity. AEs were reported in a total of nine (90.0\%) patients. As indicated in Table III, the most common $\mathrm{AE}$ of any grade was skin reaction (erythema) at the DC vaccine injection site $(n=9,90.0 \%)$. Meanwhile, fever $(n=6$, $60.0 \%$ ) was observed in six patients, including three patients $(30.0 \%)$ with Grade 1 fever $\left(>38^{\circ} \mathrm{C}\right)$. Both AEs recurred in most cases and disappeared after a few days. Grade 1 fatigue was observed in six patients $(60.0 \%)$. Grade 1 leukocytopenia,
Table III. Therapy-emergent adverse events profile of DC vaccination (Number of patients).

\begin{tabular}{|c|c|c|c|c|}
\hline & \multicolumn{4}{|c|}{ CTCAE grade } \\
\hline & 1 & 2 & 3 & 4 \\
\hline \multicolumn{5}{|l|}{ Hematological } \\
\hline Leukocytopenia & 3 & 0 & 0 & 0 \\
\hline Neutropenia & 3 & 0 & 0 & 0 \\
\hline Anemia & 1 & 0 & 0 & 0 \\
\hline Thrombocytopenia & 0 & 0 & 0 & 0 \\
\hline \multicolumn{5}{|l|}{ Non-hematological } \\
\hline Fatigue & 6 & 0 & 0 & 0 \\
\hline Nausea & 0 & 0 & 0 & 0 \\
\hline Diarrhea & 3 & 0 & 0 & 0 \\
\hline Constipation & 0 & 0 & 0 & 0 \\
\hline Anorexia & 3 & 0 & 0 & 0 \\
\hline Pain & 0 & 0 & 0 & 0 \\
\hline Hypertension & 0 & 0 & 0 & 0 \\
\hline Stomatitis & 0 & 0 & 0 & 0 \\
\hline Hematuria & 0 & 0 & 0 & 0 \\
\hline Pollakiuria & 0 & 0 & 0 & 0 \\
\hline Micturition pain & 0 & 0 & 0 & 0 \\
\hline Hand-foot syndrome & 0 & 0 & 0 & 0 \\
\hline Fever & 3 & 0 & 0 & 0 \\
\hline Injection site reaction & 9 & 0 & 0 & 0 \\
\hline AST elevation & 1 & 0 & 0 & 0 \\
\hline ALT elevation & 2 & 0 & 0 & 0 \\
\hline$\gamma$ GTP elevation & 3 & 0 & 0 & 0 \\
\hline BUN elevation & 0 & 0 & 0 & 0 \\
\hline Creatinine elevation & 0 & 0 & 0 & 0 \\
\hline UA elevation & 0 & 0 & 0 & 0 \\
\hline Hypoalbuminemia & 0 & 0 & 0 & 0 \\
\hline Hyperkalemia & 0 & 0 & 0 & 0 \\
\hline Hypokalemia & 0 & 0 & 0 & 0 \\
\hline Hyponatremia & 0 & 0 & 0 & 0 \\
\hline
\end{tabular}

neutropenia, and anemia were observed in 3,3 , and 1 of the 10 patients, respectively. Other non-hematologic AEs included grade 1 anorexia, diarrhea, hepatic transaminase, and $\gamma$ glutamyl transpeptidase elevation, all of which have been previously reported as major AEs associated with S-1 or GEM. Overall, no Grade 2 or higher CTCAE v5.0 toxicities were found to be associated with DC vaccination. Therefore, no patient discontinued DC vaccination. Although four patients died during the observation period, relapse and progression of PDA was the cause of death in all four patients as described below.

Clinical outcome. As shown in Table IV, seven of the ten patients relapsed, and the final outcome recorded six deaths because of recurrence and disease progression. The maximum follow-up period was 65 months after completion of vaccine administration. The OS and RFS from the time of surgical resection were 18.5-72.8 months (median 46.4 months) and 
Table IV. Clinical and immunological response to DC vaccination.

\begin{tabular}{|c|c|c|c|c|c|c|}
\hline \multirow[t]{2}{*}{$\begin{array}{l}\text { Patent } \\
\text { No. }\end{array}$} & \multicolumn{2}{|c|}{$\begin{array}{l}\text { Systemic adverse } \\
\text { reaction }\end{array}$} & \multirow[t]{2}{*}{$\begin{array}{l}\text { WT1-specific CTL } \\
\text { by tetramer assay }\end{array}$} & \multicolumn{2}{|c|}{$\begin{array}{c}\text { Duration after } \\
\text { the operation (days) }\end{array}$} & \multirow[t]{2}{*}{ Outcome } \\
\hline & $\mathrm{DTH}>30 \mathrm{~mm}$ & $\mathrm{KT}>38^{\circ} \mathrm{C}$ & & RFS & Survival & \\
\hline 1 & Yes & No & + & 349 & 1,805 & Dead \\
\hline 2 & No & Yes & - & 540 & 1,271 & Dead \\
\hline 3 & No & Yes & + & $>2,037$ & $>2,037$ & Alive \\
\hline 4 & No & No & $2+$ & 574 & 1,108 & Dead \\
\hline 5 & No & No & $\mathrm{NE}$ & 1,132 & 1,412 & Dead \\
\hline 6 & No & Yes & + & 410 & 766 & Dead \\
\hline 7 & Yes & No & NE & $>1,622$ & $>1,622$ & Alive \\
\hline 8 & Yes & No & NE & 358 & 1,012 & Dead \\
\hline 9 & Yes & Yes & NE & 536 & $>1,092$ & Alive \\
\hline 10 & No & No & $\mathrm{NE}$ & $>518$ & $>518$ & Alive \\
\hline
\end{tabular}

Immunological response as determined using tetramer assay; $(-),(1+)$ and $(2+)$ represent the difference in positivity between post- and prevaccination as being less than $0.1 \%$, between $0.1 \%$ and $1.0 \%$ and more than $1.0 \%$, respectively. DTH: Delayed type hypersensitivity; RFS: relapsefree survival; NE: not evaluated.

12.5-72.8 months (median 17.7 months), respectively. As shown in Figure 2, the estimated OS and RFS at 3-years were $77.8 \%(95 \% \mathrm{CI}=0.37-0.94)$ and $35.0 \%(95 \% \mathrm{CI}=0.09-0.64)$, and those at 5-year were $19.4 \%(95 \% \mathrm{CI}=0.01-0.55)$ and $23.3 \%(95 \% \mathrm{CI}=0.04-0.53)$, respectively. There were no statistically significant correlations between various clinical parameters and OS or RFS.

Immune response. As described above, a skin reaction was observed in nine of ten patients $(90.0 \%)$ after vaccination. In all nine cases, skin reactions emerged around $48 \mathrm{~h}$ after the first vaccination and recurred after each vaccination. All skin reactions were Grade I and resolved within a week. In four of nine patients, the diameters of skin reactions were measured to be over $3 \mathrm{~cm}$ (Patients 1, 7, 8, and 9). No correlations were found between skin reaction and PFS or OS.

Tetramer assays were performed for each of the five patients treated with WT1-pulsed therapy who received the HLA-A*24:02-restricted mutant WT1 peptide. WT1-specific CTLs were detected after vaccination in four patients (Table IV, Figure 3). Although positive tetramer assays and longer survival tend to be related, no statistically significant correlations were found between tetramer assay results and OS or RFS in the present study.

IHC characteristics of tumor cells and tumor microenvironment. In the present study, IHC staining revealed that WT1 protein expression was detected in the nuclei and cytoplasm of PDA samples from all patients. WT1 proteins were found to predominantly localize to the cytoplasm in all cases. Patients were subdivided into three groups according to cytoplasmic WT1 staining intensity in PDA cells: weak (4/10 cases), moderate (3/10 cases), and strong (3/10 cases) (Table I). There were no correlations between cytoplasmic WT1 intensity and various clinicopathological parameters, including age at surgical resection, sex, and tumor characteristics. The median survival time for patients with PDA with weak and moderate-to-strong cytoplasmic WT1 expression was 46.4 and 50.5 months, respectively. However, there were no correlations between the cytoplasmic WT1 staining intensity and OS or RFS. In all 3 cases that were strongly positive for WT1 (Patients 1, 3 and 4), induction of WT1-specific CTL was observed by tetramer analysis (Table I and IV, Figure 3).

IHC findings of infiltrating MNCs in tumor tissue are summarized in Table V. There were varying levels of infiltrating MNCs in all patients, and CD3-positive cells were the most common. In Patients 1, 3, and 6, there were more infiltrating CD8-positive cells than in the other cases. In eight of ten patients, there was moderate infiltration of TIA1-positive mononuclear cells. Infiltration of PD1-positive MNCs was observed in seven patients. Although the degree of infiltration of CD8 positive cells is typically associated with longer survival, no such statistically significant correlations were found between tumor-infiltrating MNC immunophenotypes and OS or RFS. Moreover, although the statistical significance was not clear because of the limited case numbers, there was a tendency for induction of WT1-specific CTL after DC vaccination in cases with a higher degree of infiltrations of $\mathrm{CD} 3+, \mathrm{CD} 4+$, or CD8+ MNCs (Figure 3).

\section{Discussion}

We report the results of a phase I/IIa clinical trial of the WT1/MUC1-DC vaccination combined with chemotherapy (mainly S-1) after resection in patients with an initial diagnosis of PDA. To the best of our knowledge, this study 


\section{Overall survival (\%)}

a

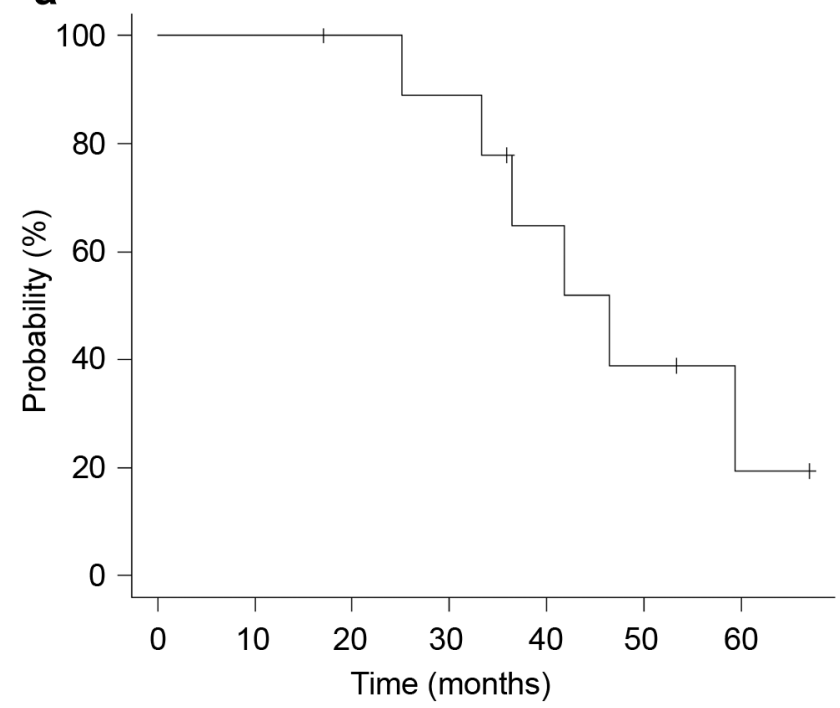

Relapse-free survival (\%)

b

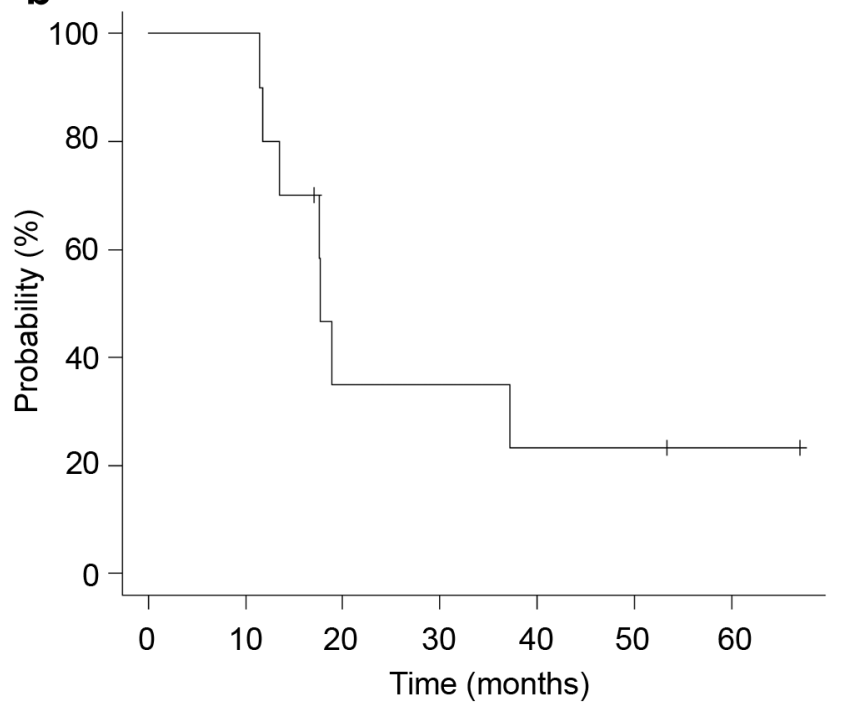

Figure 2. Kaplan-Meier plots of the survival of enrolled patients $(n=10)$ from the day of surgical resection of PDA. a) Overall survival (median 46.4 months), b) Relapse-free survival (median 17.7 months).

\begin{tabular}{|c|c|c|c|c|}
\hline \multicolumn{1}{|c}{ tet } & \multicolumn{1}{c}{ wt1 } & \multicolumn{1}{c}{ CD3 } & CD4 & CD8 \\
\hline+ & +++ & ++++ & +++ & ++++ \\
\hline+ & +++ & +++ & ++ & ++++ \\
\hline NE & ++ & +++ & + & + \\
\hline NE & + & +++ & ++++ & - \\
\hline- & ++ & ++ & - & + \\
\hline++ & +++ & +++ & ++ & + \\
\hline NE & + & ++ & + & + \\
\hline NE & ++ & + & ++ & + \\
\hline+ & + & +++ & +++ & ++++ \\
\hline NE & + & + & + & - \\
\hline
\end{tabular}

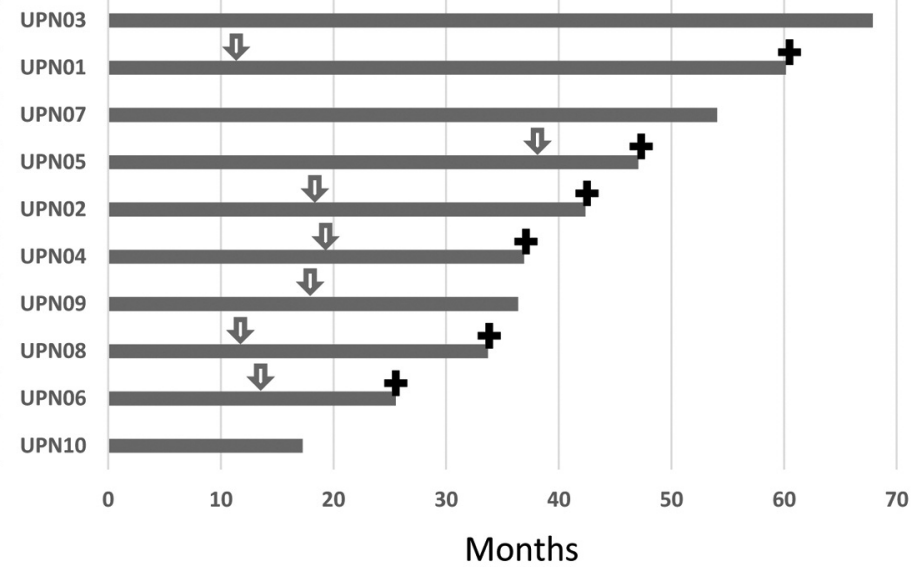

Figure 3. Correlation between clinical outcome and immunopathological findings. Numbers indicate all patients listed in Table I. Each bar graph indicates the survival period from surgical resection of the PDA tumor. Down arrows indicate time point of relapse. Cross markers indicate death of each case. tet: WT1-specific CTL by tetramer assay; wt1: expression of WT1 protein in tumor cells of PDA by IHC; NE: not evaluable. As to the description in "tet": $(-),(1+)$ and $(2+)$ represent the difference in positivity between post- and pre-vaccination as being less than $0.1 \%$, between $0.1 \%$ and $1.0 \%$ and more than $1.0 \%$, respectively. As to the description in "wt 1 ": +++; strong, ++; moderate, +; weak (25). As to the description in IHC findings for CD3, CD4, and CD8:-, <5\% of cells were positive;,$+ 5 \%$ to $10 \%$ of cells were positive;,$++ 10 \%$ to $30 \%$ were positive; +++ , $30 \%$ to $60 \%$ were positive; and,$++++>60 \%$ were positive.

is the first to report on the safety and feasibility of DC-based tumor-specific vaccination using a combination of WT1 peptide and MUC1-DC for PDA as an adjuvant setting after surgical tumor resection.
The safety profile was the primary end point. No grade 2 or higher CTCAE v4.0 toxicities were found to be associated with DC vaccination. Skin reactions at the injection site and fever were the main AEs considered to be related to DC 
Table V. Immunohistochemical profiles of infiltrating immune cells in tumor tissue.

\begin{tabular}{|c|c|c|c|c|c|c|c|c|}
\hline Patient No. & CD3 & $\mathrm{CD} 4$ & CD8 & TIA1 & $\mathrm{CD} 25$ & FOXP3 & PD1 & CD20 \\
\hline 1 & +++ & ++ & ++++ & ++ & + & + & - & - \\
\hline 2 & ++ & - & + & - & - & + & - & + \\
\hline 3 & ++++ & +++ & ++++ & ++ & ++ & - & +++ & +++ \\
\hline 4 & +++ & ++ & + & +++ & - & - & - & - \\
\hline 5 & +++ & ++++ & - & +++ & + & + & +++ & - \\
\hline 6 & +++ & +++ & ++++ & ++ & + & ++ & ++ & ++ \\
\hline 7 & +++ & + & + & ++ & + & - & + & +++ \\
\hline 8 & + & ++ & + & + & + & + & + & + \\
\hline 9 & ++ & + & + & +++ & + & ++ & ++ & - \\
\hline 10 & + & + & - & + & + & + & + & - \\
\hline
\end{tabular}

Immunohistochemistry was evaluated using high magnification light microscopy $(400 x)$ by two independent investigators. Expression was determined as negative if $<5 \%$ of cells were positive, $1+$, if $5 \%$ to $10 \%$ of cells were positive, $2+$ if $10 \%$ to $30 \%$ were positive, $3+$ if $30 \%$ to $60 \%$ were positive and $4+$ if $>60 \%$ were positive.

vaccination. These AEs were transient and manageable with symptomatic treatment and without any delay of treatment schedule. Previous reports have indicated the safety and feasibility of TAA peptide-pulsed DC vaccination as an adjuvant therapy after surgical PDA resection $(29,30)$. Lepisto et al. reported that no treatment delay occurred due to AEs in patients with PDA or biliary cancer who were treated with MUC1-pulsed DC vaccination after surgical tumor resection (29). Yanagisawa et al. have also reported that fever and skin reaction at the injection site were frequently observed but were transient and tolerable in their pilot study of WT1 peptide-pulsed DC vaccination for patients with PDA after tumor resection (30). Grade 1 fatigue in some patients was associated with fever during administration, and both were relieved concurrently. Fatigue in others was persistent, which may have been due to concomitant chemotherapy. Other hematological and nonhematological AEs were consistent with frequently observed events associated with concomitant chemotherapy. Altogether, this strategy should be considered safe and feasible for patients with PDA as an adjuvant therapy after surgical resection.

Since PS and WBC counts were well maintained even in patients who started their adjuvant chemotherapy after resection as shown in Table I, leukapheresis for harvesting DCs was carried out successfully and safely from all patients. At the time of shipment, it was confirmed that the prepared DCs had the immunophenotype of mature DCs. It has been confirmed that mature DCs produced by equivalent preparation methods have sufficient function in $\mathrm{T}$ cell proliferation stimulation and secretion of IL-12 and interferon $\gamma(\operatorname{IFN} \gamma)$ in ex vivo assays $(31,32)$. Thus, we believe that well-defined SOPs can be used to prepare sufficient quantities of stable, high-quality DC vaccines derived from autologous peripheral blood, even in the clinical setting.
In our study, the median OS and RFS were 46.4 months and 17.7 months, respectively, and the 5-years OS and RFS were $19.4 \%$ and $23.3 \%$, respectively. These results were comparable to recent findings from previous clinical trials of surgical resection followed by adjuvant chemotherapy for PDA, in which 5-year survival ranged from $10 \%$ to $25 \%$ (3335). Several phase III trials in recent years have demonstrated the survival benefit of post-resection adjuvant chemotherapy (33-36) and the usefulness of GEM or fluorouracil in the adjuvant setting (34). The JASPAC 01 study has revealed that $\mathrm{S}-1$ had better efficacy in preventing recurrence than GEM for resected PDA (36). In their study, in the S-1 group, the estimated OS at 3-years and 5 years were $59.7 \%$ and $44.1 \%$, and RFS were $39.2 \%$ and $33.3 \%$, respectively. While, 9 of 10 cases were treated with S-1 as adjuvant chemotherapy and the estimated OS and RFS at 3 years were $77.8 \%$ and $35.0 \%$, respectively, in the present study. Thus, these data suggested that the higher estimated OS at 3 years compared to JASPAC 01 study might be a unique characteristic of cancer vaccination that could not be adequately captured by the RECIST criteria. Further, add-on DC vaccination in this study enabled us to obtain data on the clinical efficacy compared to that of conventional postresection adjuvant chemotherapy. However, controversies remain regarding the immunological efficacy of the combined use of WT1 peptide and MUC1. Although it is difficult to make a rigorous comparison with the previous studies in which every single vaccination was performed (29, 30 ), its add-on effect on survival could not be clarified. Large-scale controlled trials are warranted to clarify the clinical significance of these findings. Recently, Koido et al. have shown that multiple DC vaccinations with both MHC class I and II-restricted WT1 peptides not only stimulated CTL but also maintained long-term memory $\mathrm{T}$ cells that were specific to WT1, and that this phenomenon was significantly 
linked to beneficial clinical outcomes of patients with advanced PDA (37). Therefore, the introduction of such novel vaccination methods might be associated with improvement of the long-term prognosis of patients with PDA as an adjuvant therapy.

We assessed the associations of the prognosis of PDA patients who received surgical resection with several inflammatory and immunological findings. Previous studies on several types of cancer have reported that laboratory data indicating systemic inflammatory response can serve as markers of poor prognosis in patients undergoing treatment that includes immune cellular therapy (38-40). In the present setting, NLR and CRP/albumin ratio results indicated only minimal inflammatory status in patients after resection. Thus, such a post-operative immunologic status may be favorable for immunologic induction through DC vaccination.

Our previous report has indicated that delayed skin reaction at the DC injection site may be correlated with longterm survival in DC-treated patients with advanced cancer (41). Previously, it has been indicated that such a local response represents an important source of information concerning in vivo $\mathrm{T}$ cell function and TAA-specific $\mathrm{T}$ cells (42). Thus, delayed local skin reactions may have significance regarding tumor-specific immunogenicity. However, we did not detect a significant correlation between clinical efficacy of DC vaccination or WT1-specific CTL induction detected by tetramer assay and enhancement of delayed skin reaction. Further studies are needed to clarify whether such local skin reaction after DC vaccination definitively reflects a therapeutic effect and whether monitoring skin lesions might be a simple approach to evaluate the immunogenicity of vaccination.

Recent studies have confirmed that different types of host immune cells co-exist and interact with tumor cells in the tumor microenvironment (43-45). In the networks formed between varied cellular and molecular factors, various interactions have been shown to provide important signals to initiate the growth of cancer cells and promote invasion into blood vessels and lymph nodes leading to tumor metastasis. Furthermore, it has been considered that the local immune response in the tumor microenvironment could modulate the clinical outcome and is used as a prognostic factor of solid tumors, including PDA (46). Tewari et al. (47) have shown a correlation between prognosis and the presence of tumorinfiltrating T cells. Homma et al. (48) have found that CD4+ and CD8+ cells were significantly increased after neoadjuvant chemotherapy with gemcitabine and S-1 and subsequent radiation therapy and that high CD4+ cell accumulation was an excellent prognostic marker for PDA treated with this regimen. In the present study, we did not detect statistically significant correlations between prognostic data and the degree of infiltration of various types of immune cells, although a higher degree of infiltration of
$\mathrm{CD} 3+, \mathrm{CD} 4+$, or CD8+ MNCs indicated a trend toward induction of WT1-specific CTL after DC vaccination. However, our immunohistochemical analysis was limited in scope, and considering the complexity of the tumor microenvironment, examination of additional factors is needed to clarify the clinical impact of increased infiltration following vaccination. We posit that it may be necessary to develop a combined index for this purpose. Recently, several groups have highlighted important future directions in the research of this subject $(49,50)$. In this context, resected tumor tissue may become important to predict each patient's prognosis and to develop treatment strategies including immunotherapy.

There were several limitations to this study. Due to the small number of samples analyzed, it was not possible to adequately discern the clinical effect of this treatment method, various clinical parameters, immunological findings, and association with IHC findings, including WT1 expression in tumor cells and infiltration of various immune cells. The purpose of this study was to clarify the safety and feasibility of this treatment, for which the sample size was adequate. Previous trials of DC vaccination for PDA indicated its safety and clinical effects and revealed several prognostic markers, including reduced NLR, increased expression of HLA-DR on DCs, and a lack of increased interleukin- 6 levels in peripheral blood after administration. However, these findings were in the context of advanced PDA, leaving the clinical safety, feasibility, and efficacy of this treatment unproven in the setting of resectable disease. Thus, a larger sample size will be required to clarify and confirm the clinical and biological implications of this therapy in the setting of resectable PDA. Additionally, we did not carry out testing of MUC1-specific immune reaction due to technical limitations. It is not clear whether tumor reduction by surgical resection has a differential effect on the tumor immunity obtained by the DC vaccination as compared with the case with a larger tumor burden. Thus, in vivo monitoring of TAA-specific immunity to minute residual lesions or micrometastasis might require longer-term observations than the setting of our study (30). It is necessary to clarify the clinical significance of DC vaccination and TAA-specific CTL detection by observing changes over time and by increasing the number of analysis points after DC vaccination.

In conclusion, the present phase I/IIa study evaluating WT1 peptide and MUC1-pulsed DC vaccination in combination with chemotherapy in patients with resected pancreatic cancer demonstrated the safety and feasibility of this therapy in the adjuvant setting. It was suggested that there appeared to be a survival benefit of add-on DC vaccination in this study compared to that of conventional post-resection adjuvant chemotherapy. A large-scale prospective study is warranted to evaluate the clinical benefit of this strategy and to elucidate biological markers of 
prognosis and tumor-specific immunogenicity focusing on the tumor microenvironment.

\section{Conflicts of Interest}

Nagai K. was funded for this research by Tella Inc. Adachi T., Harada H., Eguchi S., Sugiyama H. and Miyazaki Y. have no conflicts of interest directly relevant to the content of this article.

\section{Authors' Contributions}

All Authors had access to the data and participated in data collection and interpretation. K.N. and T.A. conceived and designed the study; H.H. and K.N. performed production and quality management of DC products; K.N. and T.A. acquired the data; K.N. and H.H. performed pathological observation and analysis; K.N., T.A., and S.E. analyzed and interpreted the data; H.H. performed the statistical analysis; K.N. and T.A. wrote the manuscript; H.S. provided technical advices; and S.E., H.S. and Y.M. supervised the project. All Authors approved the final version of the manuscript.

\section{Acknowledgements}

The Authors thank the patients who participated in this study and the referring surgeons who performed concomitant therapy and provided follow-up information. The Authors also thank Dr. Wataru Uegami (Department of Pathology, Nagasaki University Hospital) for his helpful advice on the pathological analysis. This study was supported in part by Grants-in-Aid for Scientific Research from the Japan Society for Promotion of Science (26221005). This study was funded by Tella Inc., Tokyo, Japan.

\section{References}

1 Ansari D, Chen BC, Dong L, Zhou MT and Andersson R: Pancreatic cancer: translational research aspects and clinical implications. World J Gastroenterol 18: 1417-1424, 2012. PMID: 22509073. DOI: 10.3748/wjg.v18.i13.1417

2 Siegel RL, Miller KD and Jemal A: Cancer statistics, 2020. CA Cancer J Clin 70: 7-30, 2020. PMID: 31912902. DOI: 10.3322/ caac. 21590

3 Nakao A, Takeda S, Inoue S, Nomoto S, Kanazumi N, Sugimoto $\mathrm{H}$ and Fujii T: Indications and techniques of extended resection for pancreatic cancer. World J Surg 30: 976-982, 2006. PMID: 16736324. DOI: 10.1007/s00268-005-0438-6

4 Yamaue H, Tsunoda T, Tani M, Miyazawa M, Yamao K, Mizuno N, Okusaka T, Ueno H, Boku N, Fukutomi A, Ishii H, Ohkawa S, Furukawa M, Maguchi H, Ikeda M, Togashi Y, Nishio K and Ohashi Y: Randomized phase II/III clinical trial of elpamotide for patients with advanced pancreatic cancer: PEGASUS-PC Study. Cancer Sci 106: 883-890, 2015. PMID: 25867139. DOI: $10.1111 /$ cas. 12674

5 Cheever MA, Allison JP, Ferris AS, Finn OJ, Hastings BM, Hecht TT, Mellman I, Prindiville SA, Viner JL, Weiner LM and Matrisian LM: The prioritization of cancer antigens: a national cancer institute pilot project for the acceleration of translational research. Clin Cancer Res 15: 5323-5337, 2009. PMID: 19723653. DOI: 10.1158/1078-0432.CCR-09-0737
6 Call KM, Glaser T, Ito CY, Buckler AJ, Pelletier J, Haber DA, Rose EA, Kral A, Yeger H, Lewis WH, Jones C and Housman DE: Isolation and characterization of a zinc finger polypeptide gene at the human chromosome 11 Wilms' tumor locus. Cell 60: 509-520, 1990. PMID: 2154335. DOI: 10.1016/0092-8674(90)90601-a

7 Gashler AL, Bonthron DT, Madden SL, Rauscher FJ 3rd, Collins $\mathrm{T}$ and Sukhatme VP: Human platelet-derived growth factor A chain is transcriptionally repressed by the Wilms tumor suppressor WT1. Proc Natl Acad Sci USA 89: 10984-10988, 1992. PMID: 1332065. DOI: 10.1073/pnas.89.22.10984

8 Harrington MA, Konicek B, Song A, Xia XL, Fredericks WJ and

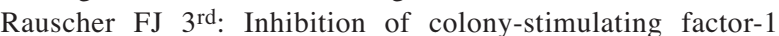
promoter activity by the product of the Wilms' tumor locus. J Biol Chem 268: 21271-21275, 1993. PMID: 8407965.

9 Drummond IA, Madden SL, Rohwer-Nutter P, Bell GI, Sukhatme

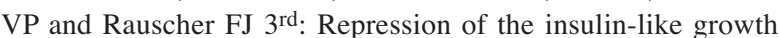
factor II gene by the Wilms tumor suppressor WT1. Science 257: 674-678, 1992. PMID: 1323141. DOI: 10.1126/science.1323141

10 Oji Y, Nakamori S, Fujikawa M, Nakatsuka S, Yokota A, Tatsumi N, Abeno S, Ikebe A, Takashima S, Tsujie M, Yamamoto H, Sakon M, Nezu R, Kawano K, Nishida S, Ikegami K, Kawakami M, Tsuboi A, Oka Y, Yoshikawa K, Aozasa K, Monden M and Sugiyama H: Overexpression of the Wilms' tumor gene WT1 in pancreatic ductal adenocarcinoma. Cancer Sci 95: 583-587, 2004. PMID: 15245594. DOI: 10.1111/j.13497006.2004.tb02490.x

11 Sugiyama H: Cancer immunotherapy targeting Wilms' tumor gene WT1 product. Expert Rev Vaccines 4: 503-512, 2005. PMID: 16117707. DOI: 10.1586/14760584.4.4.503

12 Yamasaki H, Ikeda S, Okajima M, Miura Y, Asahara T, Kohno $\mathrm{N}$ and Shimamoto F: Expression and localization of MUC1, MUC2, MUC5AC and small intestinal mucin antigen in pancreatic tumors. Int $\mathrm{J}$ Oncol 24: 107-113, 2004. PMID: 14654947.

13 Qu CF, Li Y, Song YJ, Rizvi SMA, Raja C, Zhang D, Samra J, Smith R, Perkins AC, Apostolidis C and Allen BJ: MUC1 expression in primary and metastatic pancreatic cancer cells for in vitro treatment by $213 \mathrm{Bi}-\mathrm{C} 595$ radioimmunoconjugate. Br J Cancer 91: 2086-2093, 2004. PMID: 15599383. DOI: 10.1038/ sj.bjc. 6602232

14 Levi E, Klimstra DS, Andea A, Basturk O and Adsay NV: MUC1 and MUC2 in pancreatic neoplasia. J Clin Pathol 57: 456-462, 2004. PMID: 15113850. DOI: 10.1136/jcp.2003.013292

15 Ueda M, Miura Y, Kunihiro O, Ishikawa T, Ichikawa Y, Endo I, Sekido H, Togo S and Shimada H: MUC1 overexpression is the most reliable marker of invasive carcinoma in intraductal papillary-mucinous tumor (IPMT). Hepatogastroenterology 52: 398-403, 2005. PMID: 15816444.

16 Banchereau J, Briere F, Caux C, Davoust J, Lebecque S, Liu YJ, Pulendran B and Palucka K: Immunobiology of dendritic cells. Annu Rev Immunol 18: 767-811, 2000. PMID: 10837075. DOI: 10.1146/annurev.immunol.18.1.767

17 Niccolai E, Prisco D, D'Elios MM and Amedei A. What is recent in pancreatic cancer immunotherapy? BioMed Res Int 2013: 492372, 2013. PMID: 23509731. DOI: 10.1155/2013/492372

18 Dissanayake D, Murakami K, Tran MD, Elford AR, Millar DG and Ohashi PS: Peptide-pulsed dendritic cells have superior ability to induce immune-mediated tissue destruction compared to peptide with adjuvant. PLoS ONE 9: e92380, 2014. PMID: 24647761. DOI: 10.1371/journal.pone.0092380 
19 Pelucka K and Bamchereau J: Dedritic-cell-based therapeutic cancer vaccines. Immunity 39: 38-48, 2013. PMID: 23890062. DOI: 10.1016/j.immuni.2013.07.004

20 Li W, Song X, Yu H, Zhang M, Li F, Cao C and Jiang Q: Dendritic cell-based cancer immunotherapy for pancreatic cancer. Arab J Gastroenterol 19: 1-6, 2018. PMID: 29526540. DOI: $10.1016 /$ j.ajg.2017.05.013

21 Kimura Y, Tsukada J, Tomoda T, Takahashi H, Imai K, Shimamura K, Sunamura M, Yonemitsu Y, Shimodaira S, Koido $\mathrm{S}$, Homma $\mathrm{S}$ and Okamoto M: Clinical and immunologic evaluation of dendritic cell-based immunotherapy in combination with gemcitabine and/or S-1 in patients with advanced pancreatic carcinoma. Pancreas 41: 195-205, 2012. PMID: 21792083. DOI: 10.1097/MPA.0b013e31822398c6

22 Common Terminology Criteria for Adverse Events (CTCAE) v5.0. Available at: https://ctep.cancer.gov/protocolDevelopment/ electronic_applications/ctc.htm\#ctc_50 [Last updated March 27, 2020]

23 Eisenhauer EA, Therasse P, Bogaerts J, Schwartz LH, Sargent D, Ford R, Dancey J, Arbuck S, Gwyther S, Mooney M, Rubinstein L, Shankar L. Dodd L, Kaplan R, Lacombe D and Verweij J: New response evaluation criteria in solid tumours: revised RECIST guideline (version 1.1). Eur J Cancer 45: 228247, 2009. PMID: 19097774. DOI: 10.1016/j.ejca.2008.10.026

24 Shimodaira S, Sano K, Hirabayashi K, Koya T, Higuchi Y, Mizuno Y, Yamaoka N, Yuzawa M, Kobayashi T, Ito K and Koizumi Y: Dendritic cell-based adjuvant vaccination targeting Wilms' tumor 1 in patients with advanced colorectal cancer. Vaccines 3: 1004-1018, 2015. PMID: 26690485. DOI: 10.3390/ vaccines 3041004

25 Kanai T, Ito Z, Oji Y, Suka M, Nishida S, Takakura K, Kajihara M, Saruta M, Fujioka S, Misawa T, Akiba T, Yanagisawa H, Shimodaira S, Okamoto M, Sugiyama $H$ and Koido S: Prognostic significance of Wilms' tumor 1 expression in patients with pancreatic ductal adenocarcinoma. Oncol Lett 16: 26822692, 2018. PMID: 30008944. DOI: 10.3892/ol.2018.8961

26 Ethical Guidelines for Medical and Health Research Involving Human Subjects. Available at: http://www.mhlw.go.jp/file/06Seisakujouhou-10600000-Daijinkanboukouseikagakuka/ 0000080278.pdf [Last accessed Sept 1, 2020]

27 UMIN Clinical Trials Registry (UMIN-CTR). Available at: http://www.umin.ac.jp/ctr/ [Last accessed Sept 1, 2020]

28 Classification of Pancreatic Carcinoma (4th version) by Japan Pancreas Society. Available at: http://www.suizou.org/pdf/ Classification_of_Pancreatic_Carcinoma_4th_Engl_ed.pdf [Last updated August 28, 2020]

29 Lepisto AJ, Moser AJ, Zeh H, Lee K, Bartlett D, McKolanis JR, Geller BA, Schmotzer A, Potter DP, Whiteside T, Finn OJ and Ramanathan RK: A phase I/II study of a MUC1 peptide pulsed autologous dendritic cell vaccine as adjuvant therapy in patients with resected pancreatic and biliary tumors. Cancer Ther 6: 955964, 2008. PMID: 19129927.

30 Yanagisawa R, Koizumi T, Koya T, Sano K, Koido S, Nagai K, Kobayashi M, Okamoto M, Sugiyama H and Shimodaira S: WT1pulsed dendritic cell vaccine combined with chemotherapy for resected pancreatic cancer in a Phase I study. Anticancer Res 38 : 2217-2225, 2018. PMID: 29599342. DOI: 10.21873/anticanres. 12464

31 Sato, K., Nagayama H, Tadokoro K, Juji T and Takahashi TA: Extracellular signal-regulated kinase, stress-activated protein
kinase/c-Jun N-terminal kinase, and p38mapk are involved in IL-10-mediated selective repression of TNF-alpha-induced activation and maturation of human peripheral blood monocytederived dendritic cells. J Immunol 162: 3865-3872, 1999. PMID: 10201904.

32 Sato, K., Kawasaki H, Nagayama H, Enomoto M, Morimoto C, Tadokoro K, Juji T and Takahashi TA: TGF-beta 1 reciprocally controls chemotaxis of human peripheral blood monocyte-derived dendritic cells via chemokine receptors. J Immunol 164: 22852295, 2000. PMID: 10679062. DOI: 10.4049/jimmunol.164.5.2285

33 Oettle H, Post S, Neuhaus P, Gellert K, Langrehr J, Ridwelski K, Schramm H, Fahlke J, Zuelke C, Burkart C, Gutberlet K, Kettner E, Schmalenberg H, Weigang-Koehler K, Bechstein WO, Niedergethmann M, Schmidt-Wolf I, Roll L, Doerken B and Riess H: Adjuvant chemotherapy with gemcitabine vs. observation in patients undergoing curative-intent resection of pancreatic cancer: a randomized controlled trial. JAMA 297: 267-277, 2007. PMID: 17227978. DOI: 10.1001/jama.297.3.267

34 Neoptolemos JP, Stocken DD, Bassi C, Ghaneh P, Cunningham D, Goldstein D, Padbury R, Moore MJ, Gallinger S, Mariette C, Wente MN, Izbicki JR, Friess H, Lerch MM, Dervenis C, Olah A, Butturini G, Doi R, Lind PA, Smith D, Valle JW, Palmer DH, Buckels JA, Thompson J, McKay CJ, Rawcliffe CL and Buchler MW; European Study Group for Pancreatic Cancer: Adjuvant chemotherapy with fluorouracil plus folinic acid $v s$. gemcitabine following pancreatic cancer resection: a randomized controlled trial. JAMA 304: 1073-1081, 2010. PMID: 20823433. DOI: 10.1001/jama.2010.1275

35 Oettle H, Neuhaus P, Hochhaus A, Hartmann JT, Gellert K, Ridwelski K, Niedergethmann M, Zulke C, Fahlke J, Arning MB, Sinn M, Hinke A and Riess H: Adjuvant chemotherapy with gemcitabine and long-term outcomes among patients with resected pancreatic cancer: the CONKO-001 randomized trial. JAMA 310: 1473-1481, 2013. PMID: 24104372. DOI: 10.1001/ jama.2013.279201

36 Uesaka K, Boku N, Fukutomi A, Okamura Y, Konishi M, Matsumoto I, Kaneoka Y, Shimizu Y, Nakamori S, Sakamoto H, Morinaga S, Kainuma O, Imai K, Sata N, Hishinuma S, Ojima H, Yamaguchi R, Hirano S, Suda T and Ohashi Y; JAPAC01 Study Group: Adjuvant chemotherapy of S-1 versus gemcitabine for resected pancreatic cancer: a phase 3, open-label, randomised, non-inferiority trial (JASPAC 01). Lancet 388: 248-257, 2016. PMID: 27265347. DOI: 10.1016/S0140-6736(16)30583-9

37 Koido S, Homma S, Okamoto M, Takakura K, Mori M, Yoshizaki S, Tsukinaga S, Odahara S, Koyama S, Imazu H, Uchiyama K, Kajihara M, Arakawa H, Misawa T, Toyama Y, Yanagisawa S, Ikegami M, Kan S, Hayashi K, Komita H, Kamata Y, Ito M, Ishidao T, Yusa S, Shimodaira S, Gong J, Sugiyama H, Ohkusa $\mathrm{T}$ and Tajiri $\mathrm{H}$ : Treatment with chemotherapy and dendritic cells pulsed with multiple Wilms' Tumor 1 (WT1)-specific MHC class I/II-restricted epitopes for pancreatic cancer. Clin Cancer Res 20: 4228-4239, 2014. PMID: 25056373. DOI: $10.1158 / 1078-0432 . C C R-14-0314$

38 Hotamisligil GS: Inflammation, metaflammation and immunometabolic disorders. Nature 542: 177-185, 2017. PMID: 28179656. DOI: 10.1038 /nature21363

39 Kirkegàrd J, Mortensen FV and Cronin-Fenton D: Chronic pancreatitis and pancreatic cancer risk: a systematic review and meta-analysis. Am J Gastroenterol 112: 1366-1372, 2017. PMID: 28762376. DOI: $10.1038 /$ ajg.2017.218 
40 Inman KS, Francis AA and Murray NR: Complex role for the immune system in initiation and progression of pancreatic cancer. World J Gastroenterol 20: 11160-11181, 2014. PMID: 25170202. DOI: $10.3748 /$ wjg.v20.i32.11160

41 Kobayashi M, Shimodaira S, Nagai K, Ogasawara M, Takahashi H, Abe H, Tanii M, Okamoto M, Tsujitani S, Yusa S, Ishidao T, Kishimoto J, Shibamoto Y, Nagaya M, Yonemitsu Y and DC Vaccine Study Group at the Japan Society of Innovative Cell Therapy (J-SICT): Prognostic factors related to add-on dendritic cell vaccines on patients with inoperative pancreatic cancer receiving chemotherapy: a multicenter analysis. Cancer Immunol Immunother 63: 797-806, 2014. PMID: 24777613. DOI: 10.1007/s00262-014-1554-7

42 de Vries IJ, Bernsen MR, Lesterhuis WJ, Scharenborg NM, Strijk SP, Gerritsen MJ, Ruiter DJ, Figdor CG, Punt CJA and Adema GJ: Immunomonitoring tumor-specific $\mathrm{T}$ cells in delayed-type hypersensitivity skin biopsies after dendritic cell vaccination correlates with clinical outcome. J Clin Oncol 23: 5779-5787, 2005. PMID: 16110035. DOI: 10.1200/JCO.2005.06.478

43 Quail DF and Joyce JA: Microenvironmental regulation of tumor progression and metastasis. Nat Med 19: 1423-1437, 2013. PMID: 24202395. DOI: 10.1038/nm.3394

44 Li J, Byrne K, Yan F, YamazoeT, Chen A, Baslan T, Richman LP, Lin JH, Sun YH, Rech AJ, Balli D, Hay CA, Sela Y, Merrell AJ, Liudahl SM, Gordon N, Norgard RJ, Yuan S, Yu S, Chao T, Ye S, Eisinger-Mathason TSK, Faryabi RB, TobiasJW, Lowe SW, Coussens LM, Wherry EJ, Vonderheide RH and Stanger BZ: Tumor cell-intrinsic factors underlie heterogeneity of immune cell infiltration and response to immunotherapy. Immunity 49: 178-193, 2018. PMID: 29958801. DOI: 10.1016/ j.immuni.2018.06.006

45 Foucher ED, Ghigo C, Chouaib S, Galon J, Iovanna J and Olive D: Pancreatic ductal adenocarcinoma: a strong imbalance of good and bad immunological cops in the tumor microenvironment. Front Immunol 9: 1044, 2018. PMID: 29868007. DOI: 10.3389/ fimmu.2018.01044
46 Lianyuan T, Xiu D, Chunhui Y, Zhaolai M and Bin J: The predictive value and role of stromal tumor-infiltrating lymphocytes in pancreatic ductal adenocarcinoma (PDAC). Cancer Biol Ther 19: 296-305, 2018. PMID: 29313457. DOI: 10.1080/153840 47.2017.1416932

47 Tewari N, Zaitoun AM, Arora A, Madhusudan S, Ilyas M and Lobo DN: The presence of tumourassociated lymphocytes confers a good prognosis in pancreatic ductal adenocarcinoma: an immunohistochemical study of tissue microarrays. BMC Cancer 13: 436, 2013. PMID: 24063854. DOI: $10.1186 / 1471$ 240713436

48 Homma Y, Taniguchi K, Murakami T, Nakagawa K, Nakazawa M, Matsuyama R, Mori R, Takeda K, Ueda M, Ichikawa Y, Tanaka $\mathrm{K}$ and Endo I: Immunological impact of neoadjuvant chemoradiotherapy in patients with borderline resectable pancreatic ductal adenocarcinoma. Ann Surg Oncol 21: 670-676, 2014. PMID: 24310792. DOI: 10.1245/ s104340133390y

49 Teng MWL, Ngiow SF, Ribas A, and Smyth MJ: Classifying cancers based on Tcell infiltration and PDL1. Cancer Res 75: 2139-2145, 2015. PMID: 25977340. DOI: 10.1158/00085 472.can 150255

50 Mahajan UM, Langhoff E, Goni E, Costello E, Greenhalf W, Halloran C, Ormanns S, Kruger S, Boeck S, Ribback S, Beyer G, Dombroswki F, Weiss FU, Neoptolemos JP, Werner J, D’Haese JG, Bazhin A, Peterhansl J, Pichlmeier S, Buchler MW, Kleeff J, Ganeh P, Sendler M, Palmer DH, Kohlmann T, Rad R, Regel I, Lerch MM and Mayerle J: Immune cell and stromal signature associated with progression-free survival of patients with resected pancreatic ductal adenocarcinoma. Gastroenterology 155: 16251639, 2018. PMID: 30092175. DOI: 10.1053/j.gastro.2018.08.009

Received August 17, 2020

Revised August 31, 2020

Accepted September 1, 2020 